\title{
Therapeutic effects of syringaldehyde on spinal cord ischemia in rabbits
}

\author{
Ümit A. Malçok, MD, Adem B. Aras, MD, Müşerref H. Şehitoğlu, MD, Tarık Akman, MD, Yasemin Yüksel, MD.
}

\begin{abstract}
الأهداف : دراسة آثار مركب (SA) ) على نظام مضادات الأكسدة والأكسدة في ) كلي

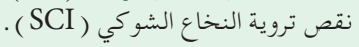

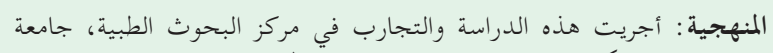

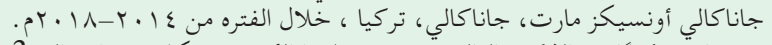

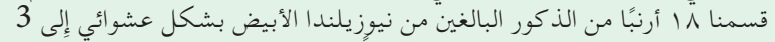

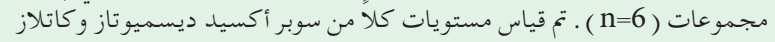

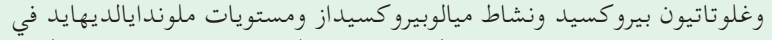

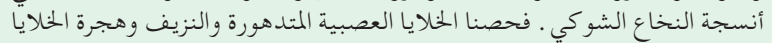

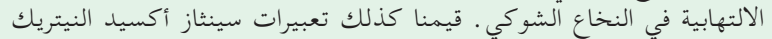

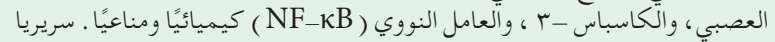
، تم تقييمه مع درجة تعديل تاربار، والعل النوف

النتائج : من الناحية البيو كيميائية ، كان هناك انخفاض متوقع في أنشٍ فِ إِنزيم

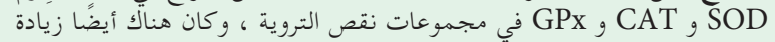

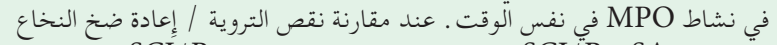

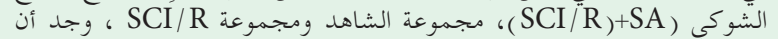

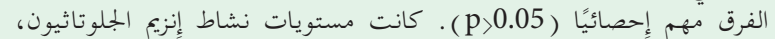

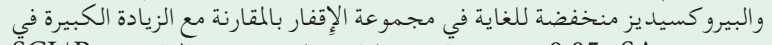

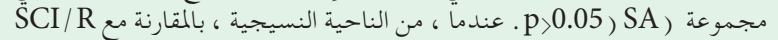

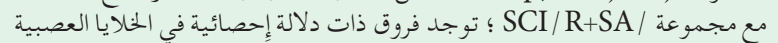

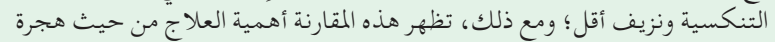

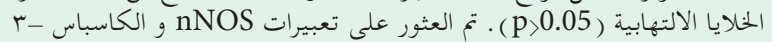

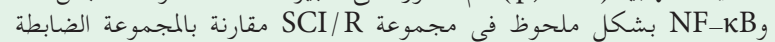

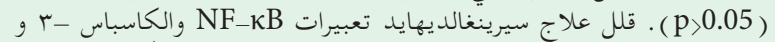
تعبيرات NF-KB المناعيه الكيميائيه . أظهر التقييم السريري تحسنًا في المجموعة

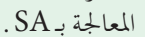

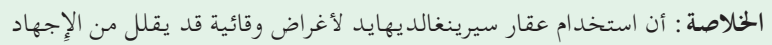

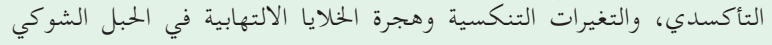

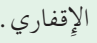

Objectives: To investigate the effects of syringaldehyde (SA) on the antioxidant and oxidant system in spinal cord ischemia (SCI).

Methods: These study and experiments were conducted at Medical Research Center, Çanakkale Onsekiz Mart University, Çanakkale, Turkey, between 2014-2018. Eighteen New Zealand White adult male rabbits were randomly divided into 3 groups $(\mathrm{n}=6)$. Superoxide dismutase (SOD), catalase (CAT), glutathione peroxidase (GPx), myeloperoxidase (MPO) activities, and malondialdehyde (MDA) levels were measured in the spinal cord tissues. Degenerated neurons, hemorrhage and inflammatory cell migration in the spinal cord were investigated histopathologically. Expressions of neuronal nitric oxide synthase (nNOS), caspase-3, and nuclear factor- $\kappa \mathrm{B}(\mathrm{NF}-\kappa \mathrm{B})$ were evaluated immunohistochemically. Clinically, it was evaluated with Modified Tarlov score.

Results: Biochemically, there was an expected decrease in SOD, CAT, and GPx enzyme activities in ischemia groups, there was also an increase in MPO activity at the same time. When the enzyme activities spinal cord ischemia/ reperfusion $(\mathrm{SCI} / \mathrm{R})+\mathrm{SA}$, control and SCI/R groups were compared, the difference was found to be statistically significant $(p<0.05)$. Glutathione peroxidase enzyme activity levels were very low in ischemia group compared to the significant increase in the SA group $(p<0.05)$. Histopathologically, when SCI/R and SCI/R+SA groups were compared, there were statistically significant differences in the number of degenerative neurons and amount of hemorrhage; this comparison shows the significance of treatment in terms of inflammatory

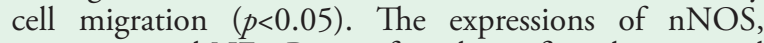
caspase-3, and NF- $\mathrm{NB}$ were found significantly increased in SCI/R group compared to the control group $(p<0.05)$. Syringaldehyde treatment decreased nNOS, caspase-3, and NF- $\mathrm{NB}$ expressions immunohistochemically. Clinical evaluation showed improvement in the SA-treated group.

Conclusion: Syringaldehyde therapy administered for protective purposes may reduce oxidative stress, degenerative changes and inflammatory cell migration in the ischemic spinal cord.

Keywords: syringaldehyde, oxidative stress, spinal cord ischemia, nerve regeneration

Saudi Med J 2020; Vol. 41 (4): 341-350

doi: 10.15537/smj.2020.4.24993

From the Department of Neurosurgery (Malçok, Aras, Akman), from the Department of Biochemistry (Şehitoğlu), School of Medicine, Çanakkale Onsekiz Mart University, Chanakkale; and from the Department of Histology-Embryology (Yüksel), Zekai Tahir Burak Research Hospital, Ankara, Turkey.

Received 2nd September 2019. Accepted 4th February 2020.

Address correspondence and reprint request to: Dr. Ümit A. Malçok, Department of Neurosurgery, School of Medicine, Çanakkale Onsekiz Mart University, Çanakkale, Turkey.E-mail: umalcok@comu.edu.tr ORCID ID: https://orcid.org/0000-0002-1272-9654 
$S^{\mathrm{S}}$ pinal cord ischemia (SCI) is a condition with high morbidity and mortality, especially in the elderly. To prevent SCI, the pathophysiology of ischemia should be understood first. Ischemia-induced and postischemia reperfusion damages are significant reasons for morbidity. ${ }^{1-3}$ The inflammatory response after ischemia is another important factor to consider. Additionally, the release of cytokines increases and disrupts the blood-tissue barrier after the inflammatory response. ${ }^{4}$ The deterioration of protein synthesis after ischemia matters as well. Irreversible damage to the spinal cord tissue occurs as protein synthesis deteriorates. ${ }^{5}$ Hence, preventing the development of irreversible damage should be the purpose of ischemia treatment.

Syringaldehyde (SA) is a polyphenolic compound from the flavonoid group. ${ }^{6}$ Flavonoids are low-molecular weight polyphenolic compounds frequently found in plants. Their antioxidant, antithrombotic, antihypertensive, anti-inflammatory, and anticarcinogenic effects have been shown in many studies. ${ }^{6,7}$ We aimed to investigate the effects of SA therapy on SCI. We believe that the resulting data can also be utilized to guide practitioners in the proper management of SCI in the future.

Methods. Animals and treatment. Eighteen New Zealand White adult male rabbits (weighing $2.5-3 \mathrm{~kg}$ ) were obtained from the Experimental Research Center of the Çanakkale Onsekiz Mart University, Çanakkale, Turkey. The rabbits were hosted in plastic cages at $19^{\circ} \mathrm{C}$ to $23^{\circ} \mathrm{C}$ room temperature. They were provided with 12 hours light/dark cycle daily and fed with standard rabbit chow (Bil-Yem Ltd., Ankara, Turkey) as needed. These study and experiments were conducted at Medical Research Centre, Çanakkale Onsekiz Mart University, Çanakkale, Turkey, between 2014 and 2018. The experiments were conducted with permission from Çanakkale Onsekiz Mart University Animal Ethics Board (File number 2014/129, Decision number: 2014/11-09).

The rabbits were randomly divided into 3 groups with 6 animals in each group. Group 1 was the control $(n=6)$, with no surgical intervention and medication and

Disclosure. Authors have no conflict of interests, and the work was not supported or funded by any drug company. This study was funded by the Scientific Research Coordination Unit, Çanakkale Onsekiz Mart University, Çanakkale, Turkey (Project Number: TSA-2015-438). was only sacrificed. Group 2 was the spinal cord ischemia/ reperfusion (SCI/R) $(n=6)$, with SCI/R+single dose of 1 $\mathrm{mL}$ of $10 \%$ ethanol administered intraperitoneally and sacrificed after 24 hours. Group 3 is the SCI/R+SA $(\mathrm{n}=6)$ with $10 \mathrm{mg} / \mathrm{kg}$ SA added to $1 \mathrm{~mL}$ of $10 \%$ ethanol administered intraperitoneally after SCI/R and sacrificed after 24 hours.

Surgical methods. Ketamine (Ketalar, Eczacıbaşı, Istanbul, Turkey) at a dose of $10 \mathrm{mg} / \mathrm{kg}$ was administered intramuscularly as premedication to all animals before the experiment. A $24 \mathrm{G}$ arterial catheter was inserted, followed by a $26 \mathrm{G}$ venous catheter. For the induction of anesthesia, $2 \mathrm{mg} / \mathrm{kg}$ of ketamine, $1 \mu \mathrm{g} / \mathrm{kg}$ of fentanyl, and $0.5 \mathrm{mg} / \mathrm{kg}$ of rocuronium bromide were administered. Supratracheal intubation (V-gel rabbit) was performed on all animals for airway safety after sufficient muscle relaxation was achieved. During the induction of anesthesia and performance of surgical procedure, anesthesia was sustained with $1 \%$ isoflurane, observing 1:1 oxygen/air mixture. Arterial monitorization and blood gas follow-ups were performed on all rabbits. Laparotomy was carried out through a standardized incision after sterile dressing of the operation site. After retracting the intestines, the retroperitoneum was then opened, and the infrarenal abdominal aorta was exposed. The aorta was cross-clamped from both sides, and loss of aortic pulsation from the area distal to the left renal artery and proximal to the aortic bifurcation was confirmed by palpation. The duration of ischemia was maintained for 45 minutes, and then the cross-clamp was removed and reperfused for 15 minutes. Distal perfusion was visually observed after removing the crossclamp. Monitorization was carried out using the Biopac MP36 (BIOPAC Systems, Inc. Goleta, CA, USA) device. The mean arterial pulse was maintained between 250 and 300/min during the surgical procedure. The body temperature was monitored using a rectal probe and set using a heating pad at $37.1^{\circ} \mathrm{C}$ to $37.4^{\circ} \mathrm{C}$. At the end of the procedure, the abdominal wall was closed using a 3-0 prolene suture, and the operation was terminated. The animals were caged after awakening from the surgery.

The subjects were taken back to the laboratory to be sacrificed after 24 hours. One $\mathrm{mg} / \mathrm{kg}$ of rocuronium, $10 \mathrm{mg} / \mathrm{kg}$ of ketamine, and $2 \mu \mathrm{g} / \mathrm{kg}$ of fentanyl were administered intravenously to the rabbits. Subjects were anesthetized and monitored during spinal cord sampling. Continuous blood circulation was observed when the samples were taken. The spinal cord was removed rapidly through the posterior approach between the T6 and L3. Each spinal cord is longitudinally divided into 2 equal parts. Sacrificial procedures were 
performed by decapitating the rabbits after taking the spinal cord samples. One of the symmetrical halves of the longitudinally separated spinal cord was reserved for histopathological examination and the other half for biochemical analysis. The tissues for histopathological examination were fixed in formalin for one week, whereas the tissues separated for biochemical tests were stored at $-80^{\circ} \mathrm{C}$.

Biochemical analysis. Tissue samples stored at $-80^{\circ} \mathrm{C}$ were taken for biochemical assays. The tissues were homogenized in appropriate buffer media prepared separately to be used for each method, and the supernatants were collected. Superoxide dismutase (SOD), catalase (CAT), glutathione peroxidase (GPx) and myeloperoxidase (MPO) activities and malondialdehyde (MDA) levels were measured using a sensitive ELISA spectrophotometer. Two repetitive analyses were carried out from each sample. Total protein concentrations were determined according to the Bradford method (Sigma-Aldrich, Bradford reagent-B6916-1KT, USA). All results were expressed as mean \pm standard deviation (SD) for $1 \mathrm{mg}$ of protein.

Glutathione peroxidase-Px or GPx activity. Glutathione peroxidase (glutathione: $\mathrm{H}_{2} \mathrm{O}_{2}$ oxidoreductase; EC 1.11.1.9) is the enzyme responsible for the reduction of hydroperoxides. Glutathione peroxidase is found in mammalian cells and helps to inhibit lipid peroxidation of receiver cell membranes. Glutathione peroxidase activities of spinal cord tissues were determined by ELISA spectrophotometer using the commercially available ENZO, ADI-900-158, Glutathione Peroxidase activity kit. The results were expressed as $\mathrm{U} / \mathrm{mL}(\mathrm{U} / \mathrm{mL}$.mg. protein) per $\mathrm{mg}$. protein (Table 1).

Superoxide dismutase activity. Superoxide dismutase (EC 1.15.1.1) is an antioxidant enzyme that catalyzes the conversion of superoxide free radicals $\left(\mathrm{O}_{2}^{-}\right)$to hydrogen peroxide $\left(\mathrm{H}_{2} \mathrm{O}_{2}\right)$ and molecular oxygen $\left(\mathrm{O}_{2}\right)$. Superoxide dismutase activity IC50 (50\% inhibition of SOD activity) values were determined colorimetrically at $450 \mathrm{~nm}$, using the SOD assay kit (Sigma-Aldrich19160-St. Louis, Mo., USA). The results were expressed as $\mathrm{U} / \mathrm{mL}$ (U/mL.mg. protein) per $\mathrm{mg}$. of protein (Table 1).

Catalase activity. Catalase $\quad\left(\mathrm{H}_{2} \mathrm{O}_{2}: \quad \mathrm{H}_{2} \mathrm{O}_{2}\right.$ oxidoreductase; EC 1.11.1.6) is a hemoprotein with 4 heme groups in its structure. It is an antioxidant enzyme that breaks down $\mathrm{H}_{2} \mathrm{O}_{2}$ into water and oxygen without producing free radicals. Catalase activities of rabbit spinal cord tissues were determined by STA-341, Cell Biolabs' Oxiselect ${ }^{\mathrm{TM}}$ Catalase Activity Assay, Colorimetric commercial kit. The results obtained by the ELISA spectrophotometer were expressed as U/mL (U/mL.mg. protein) per mg. protein (Table 1).

Myeloperoxidase activity. Myeloperoxidase is a protein that is abundantly released from activated neutrophils and monocytes in response to inflammation. Myeloperoxidase activity is increased when reactive oxidation products cause tissue damage. The STA-803 Cell Biolabs' OxiSelect ${ }^{\mathrm{TM}}$ Myeloperoxidase Chlorination Activity Assay (Colorimetric) commercial kit was used to determine MPO activities of rabbit spinal cord. Results from ELISA spectrophotometry were expressed as $\mathrm{mU} / \mathrm{mL}$ (mU/mL.mg. protein) per mg. protein (Table 1).

Lipid peroxidation, MDA measurement. Lipid peroxidation was determined by measuring the color intensity of the resulting product of MDA and thiobarbituric acid (TBA) reaction at $532 \mathrm{~nm}$. The STA-330 Cell Biolabs' OxiSelect ${ }^{\mathrm{TM}}$ TBARS Assay (MDA Quantitation) commercial kit was used to determine the MDA levels in our study. The results were expressed as $\mu \mathrm{mole} / \mathrm{mL}$ ( $\mu \mathrm{mole} / \mathrm{mL} . \mathrm{mg}$. protein) per mg. protein (Table 1).

Histopathological evaluation. The spinal cord samples to be used in histopathological examinations were fixed in $10 \%$ neutral formalin. The samples were routinely processed, embedded in paraffin, cut into sections with $5 \mu \mathrm{m}$ thickness, and stained with hematoxylin-eosin $(\mathrm{H} \& \mathrm{E})$ and $0.01 \%$ Cresyl violet. The slides were examined for hemorrhage, inflammatory cell migration, and neuron injury. Hemorrhage and inflammatory cell migration were scored semi-quantatively as follows: 0 as normal, 1 as mild, 2 as moderate, and 3 as severe. The number of morphologically degenerated neurons in the gray matter of the spinal cord was determined under a light microscope (Eclipse E-600, Nikon, Japan) using an image analysis system (NIS Elements Nikon, Japan). Degenerated neurons can be identified through their dense eosinophilic cytoplasm, Nissl substance loss, and pyknotic nuclei. Viable neurons were identified by the presence of loose nuclear chromatin and Nissl substance in the cytoplasm.

Immunohistochemical staining of caspase-3, nuclear factor-KB $(N F-\kappa B)$, and neuronal nitric oxide synthase (nNOS). Samples from spinal cords were deparaffinized and stained with caspase-3, NF- $\kappa \mathrm{B}$, and nNOS immunohistochemically. Citrate buffer $(\mathrm{pH}=6.0)$ was used for antigen retrieval by placing the samples in a microwave for 25 minutes. Then sections were washed in Tris-buffered saline (TBS) Tween 20, and endogenous peroxidase activity was blocked using 3\% hydrogen peroxidase in methanol for 12 minutes. After being washed in TBS, ultraviolet-blocking solution 
was applied to the sections for 5 minutes; without washing, sections were incubated with caspase-3 (1:100 dilution; MA116843, Thermo Scientific), NF-кB p65 (1:150 dilution; RB-1638-P1, Thermo Scientific), and nNOS (1:100 dilution; PA3-032A, Thermo Scientific) primary antibodies at $4^{\circ} \mathrm{C}$ overnight. Horseradish peroxidase (HRP) secondary antibody kit (Antipolyvalent HRP, Labvision Corp, Fremont, CA) was applied as a secondary antibody, and AEC kit was used as chromogen (Labvision Corp, Fremont, CA). Finally, counterstaining was carried out using Mayer's hematoxylin, and slides were placed in a mounting medium. Immunopositive motor neurons in the gray matter were counted in each section.

Statistical analysis. Statistical analysis was performed using SPSS 21.0 (SPSS Inc., USA). Statistical significance was accepted as $p<0.05$. All data were expressed as mean $\pm S D$ for each variable. Data were subjected to one-way analysis of variance (ANOVA) for biochemical analysis; differences between the groups were evaluated using the Tukey post-hoc option. Kruskal-Wallis test was used for histopathological analysis of the presence of degenerated neurons and immunostainings in the groups, and Iman-Conover test was used for pairwise comparisons. Chi-square test was applied to analyze hemorrhage and inflammatory cell migration.

Neurological score evaluation. Modified Tarlov scale was used for neurological scoring of the subjects. ${ }^{8}$ The neurological status of the animals was assessed by a neurologist after the intervention. On this scale, scores from zero to 5 were used. Scoring system is as follows: 0 for no movement at the lower extremity, 1 for movement at the lower limb with eliminated gravity, 2 for motion at the lower limb against gravity, 3 for able to stand with help, 4 for able to walk with assistance, and 5 for normal.

Results. Biochemical results. When the results obtained from the biochemical analyses were examined (Table 1), an expected decrease in SOD, CAT, and GPx enzyme activities in the ischemia groups was observed. An increase in MPO activity was also observed at the same time. Statistical differences were found when the analysis results of the control and ischemia groups were compared with the SA group, supporting the therapeutic efficacy of SA $(p<0.05)$.

As a result of the examination of GPx values, very low enzyme activity values were found in the ischemia group. However, there was a significant increase in the SA-treated group $(p<0.05)$.

Histopathological results. Hemotoxylin and Eosin and Cresyl violet staining results. The means of degenerated motor neuron, hemorrhage, and inflammatory cell migration were shown in Figures $1 \& 2$ and Table 2. Spinal cord specimens in the control group had normal appearance (Figures 1A \& 2A). Moderate hemorrhage and inflammatory cell infiltration in the gray matter were observed in the SCI/R group (Figures 1B \& 2B, Table 2). The number of degenerated motor neurons was significantly higher after ischemia when compared with that in the control group $(p<0.05)$ (Table 2). A slight decrease in hemorrhage (Table 2) and inflammatory cell migration was observed in the SA-treated group as compared with the SCI/R group ( $p<0.05)$ (Figures 1C \& 2C). The application of SA resulted in a decrease in the number of degenerated motor neurons, which is lower than that in the ischemia group (Table 2).

Results of caspase-3 immunohistochemical staining. Caspase-3 primer antibody was used to assess

Table 1 - Superoxide dismutase (SOD), catalase (CAT), glutathione peroxidase (GPX) and myeloperoxidase (MPO) activities and malondialdehyde (MDA) levels in rabbit spinal cord tissues.

\begin{tabular}{|c|c|c|c|c|c|}
\hline Groups & $\begin{array}{c}\text { SOD } \\
\text { (U/ml.mg. } \\
\text { protein) }\end{array}$ & $\begin{array}{c}\text { CAT } \\
(\mathrm{U} / \mathrm{ml} . \mathrm{mg} \text {. protein })\end{array}$ & $\begin{array}{c}\text { GPX } \\
\text { (U/ml.mg. protein) }\end{array}$ & $\begin{array}{c}\text { MPO } \\
\text { (mU/ml.mg. } \\
\text { protein) }\end{array}$ & $\begin{array}{c}\text { MDA } \\
(\mu \mathrm{mole} / \mathrm{ml} . \mathrm{mg} . \\
\text { protein) }\end{array}$ \\
\hline Control & $7.20 \pm 0.84^{\S}$ & $25.12 \pm 2.08^{*}$ & $38.77 \pm 5.04^{*}$ & $16.73 \pm 1.69^{\S}$ & $18.93 \pm 4.56^{\S}$ \\
\hline $\mathrm{SCI} / \mathrm{R}^{\mathrm{R}}$ & $3.29 \pm 0.47^{\dagger}$ & $13.99 \pm 1.10^{\ddagger}$ & $1.98 \pm 0.76^{\S}$ & $33.13 \pm 2.35^{\dagger \dagger}$ & $29.53 \pm 3.95^{* *}$ \\
\hline $\mathrm{SCI} / \mathrm{R}+\mathrm{SA}$ & $5.38 \pm 0.70^{*}$ & $21.31 \pm 2.32^{*}$ & $33.21 \pm 3.58^{*}$ & $22.52 \pm 2.36^{*}$ & $23.98 \pm 3.52^{*}$ \\
\hline$P$-values & 0.000 & 0.001 & 0.000 & 0.000 & 0.001 \\
\hline \multicolumn{6}{|c|}{ 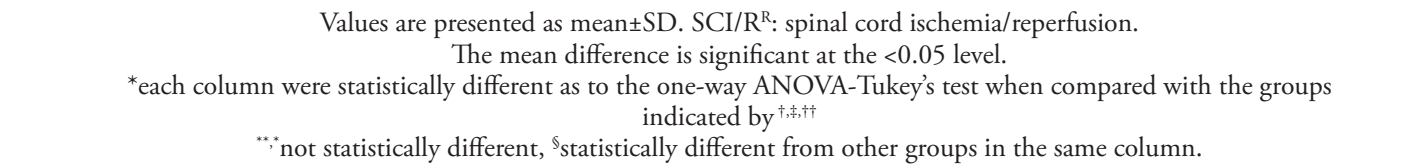 } \\
\hline
\end{tabular}




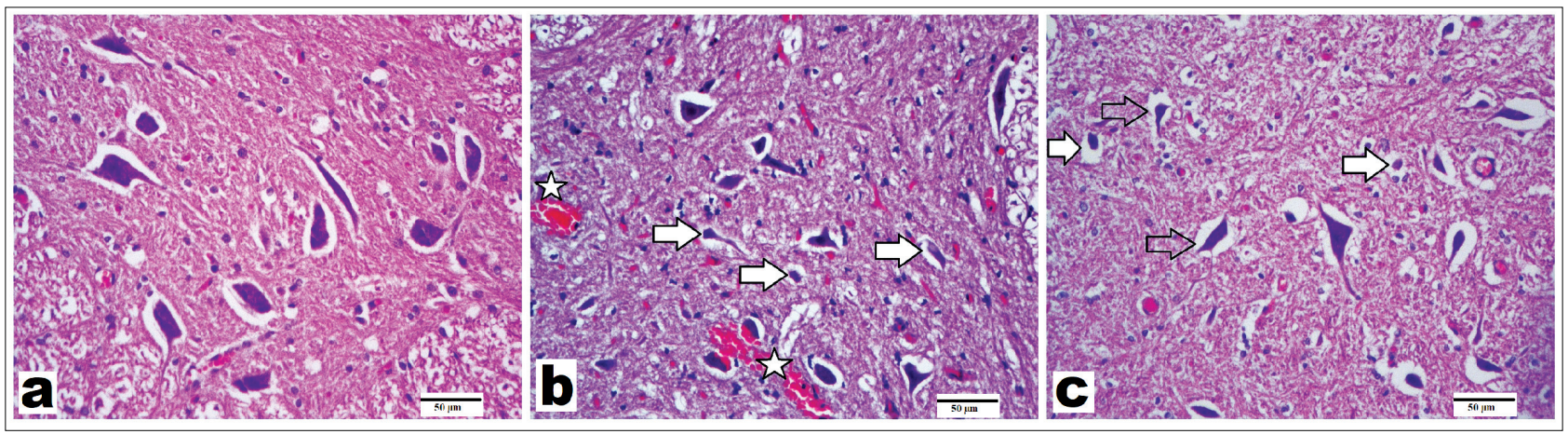

Figure 1 - Representative images of the spinal cords stained with hematoxylin and eosin $(\mathrm{x} 200$, scale bar $=50 \mu \mathrm{m})$. Normal neurons exhibited a fine basophilic granular cytoplasm with Nissl body. Dead or degenerated neurons were defined by the presence of cytoplasmic shrinkage and eosinophilic cytoplasm and loss of Nissl body. A) Control group: showing normal structure and viable motor neurons; B) spinal cord ischemia/ reperfusion (SCI/R) group: showing increase in degenerated motor neurons; $\mathrm{C}$ ) syringaldehyde-treated SCI/R group showing less degeneration in motor neurons. Asterisks show hemorrhage. Arrows refer to degenerated motor neurons. Hollow arrows show slightly degenerated motor neurons.

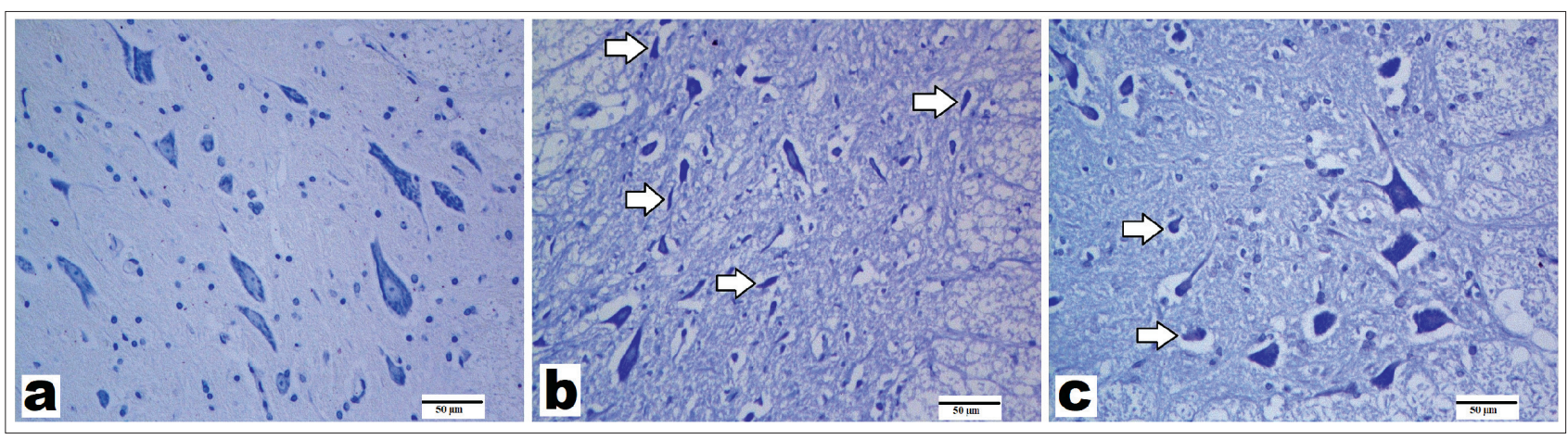

Figure 2 - Representative images of spinal cord sections stained with Cresyl violet (x200, scale bar $=50 \mu \mathrm{m})$. A) Control group, viable neurons showing regular nuclei and cytoplasm; B) SCI/R group, showing degenerated motor neurons (arrows); C)syringaldehyde-treated group, showing less affected degenerated neurons from the spinal cord ischemia/reperfusion (SCI/R).

Table 2 - Degenerated motor neuron counts in the gray matter, hemorrhage, and inflammatory cell migration scores from the experimental groups.

\begin{tabular}{lccc}
\hline $\begin{array}{l}\text { Scored } \\
\text { histopathological } \\
\text { changes }\end{array}$ & Control & $\begin{array}{c}\text { Groups } \\
\text { SCI/R }\end{array}$ & SCI/R+SA \\
\hline $\begin{array}{l}\text { The number of } \\
\text { degenerated motor } \\
\text { neurons }\end{array}$ & $3.50 \pm 1.05^{\mathrm{a}}$ & $48.00 \pm 5.93^{\mathrm{b}}$ & $36.83 \pm 5.84^{*}$ \\
$\begin{array}{l}\text { Hemorrhage } \\
\begin{array}{l}\text { Inflammatory cell } \\
\text { migration }\end{array}\end{array}$ & $0.17 \pm 0.41^{\mathrm{c}}$ & $1.50 \pm 0.54^{\mathrm{d}}$ & $1.17 \pm 0.75^{\dagger}$ \\
\hline
\end{tabular}

Data were presented as mean \pm SD. In each line, the difference between the means with the same letters is significant $(p<0.05)$.

Groups in the same row, respectively; between the group "*” and the groups "a" and "b," between the group "†" and the groups "c" and "d," and between the group "”" and the groups "e" and "f"; there are significant differences supporting the curative effect of SCI/SA: spinal cord ischemia syringaldehyde $(p<0.05)$. apoptotic changes. Caspase-3 immunohistochemistry images are shown in Figure 3; mean scores are given in Table 3. Cytoplasmic positivity was considered positive in all immunostainings. Some motor neurons exhibited caspase-3-positive staining in the control group (Figure 3A, Table 3). Spinal cord ischemia/ reperfusion injury markedly increased the number of caspase-3-positive motor neurons. This increase was statistically significant when compared with the control group ( $p=0.0001$ ) (Table 3, Figure 3B). The number of positive cells in the SA-treated group that was stained with caspase-3 decreased when compared with that in the SCI/R group (Table 3, Figure 3C); a significant difference was observed between SCI/R and SA group.

$N F-\kappa B$ immune staining. Nuclear factor- $\mathrm{KB}$ has an important role in the activation of inflammatory and immune responses that can cause cellular damage. 


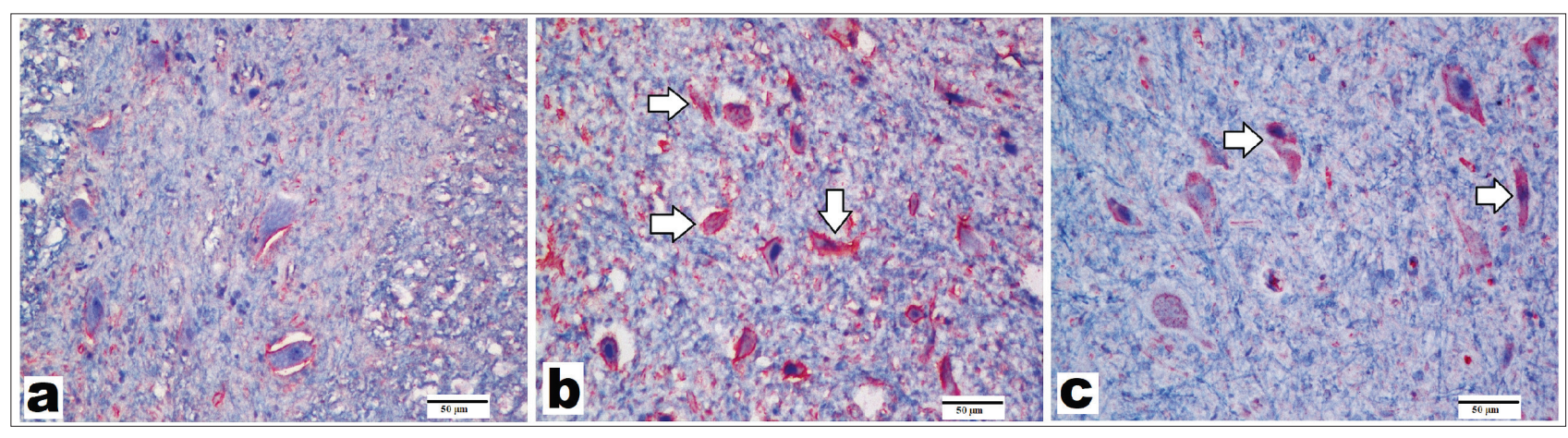

Figure 3 - Representative images of caspase-3 immunostaining of spinal cords ( $\mathrm{x} 200$, scale bar=50 $\mu \mathrm{m}$ ). A) In the control group, few neurons revealed caspase-3-positive staining. B) In the spinal cord ischemia/reperfusion (SCI/R) group, increased number of caspase-3 positivity was observed in the motor neurons. C) Caspase-3 positivity was visible in some neurons in the syringaldehyde-treated group after ischemia, but the number of caspase-3-positive cells was lower than that in SCI/R the group. Arrows refer to caspase-3-positive staining in the motor neurons in the gray matter.

Table 3 - The number of caspase-3, nuclear factor kappa B (NF-кB), and neuronal nitric oxide synthase (nNOS)-positive motor neurons in the gray matter from the experimental groups.

\begin{tabular}{lccc}
\hline Expression & \multicolumn{3}{c}{ Groups } \\
& Control & SCI $/ \mathrm{R}$ & SCI $/ \mathrm{R}+\mathrm{SA}$ \\
\hline Caspase-3 & $5.17 \pm 1.72^{\mathrm{a}}$ & $27.67 \pm 5.35^{\mathrm{b}}$ & $17.17 \pm 2.93^{\mathrm{c}}$ \\
NF- $\mathrm{KB}$ & $5.17 \pm 1.72^{\mathrm{a}}$ & $34.33 \pm 11.88^{\mathrm{b}}$ & $17.67 \pm 5.16^{\mathrm{c}}$ \\
nNOS & $5.50 \pm 1.87^{\mathrm{a}}$ & $25.00 \pm 8.15^{\mathrm{b}}$ & $18.67 \pm 3.33^{\mathrm{c}}$ \\
\hline
\end{tabular}

Data were presented as mean \pm SD. In each line, the difference between the means with the same letters is significant $(p<0.05)$. SCI/R: spinal cord ischemia/reperfusion, SCI/SA: spinal cord ischemia syringaldehyde

NF- $\kappa \mathrm{B}$ immunohistochemistry images are shown in Figure 4; mean scores were shown in Table 3. The control group exhibited minimal NF- $\kappa \mathrm{B}$ expression in motor neurons (Figure 4A, Table 3). Moreover, there was a statistically significant increase in NF- $\mathrm{KB}$ expression after SCI/R injury compared with that in the control group ( $p=0.0001$ ) (Table 3, Figure 4B). The SA-treated group showed reduced NF- $\mathrm{KB}$ expression (Figure $4 \mathrm{C}$, Table 3).

nNOS Immunohistochemical staining. It is known that nNOS levels usually increase in the neurons after ischemic damage. Images of $\mathrm{nNOS}$ immunohistochemistry are shown in Figure 5; mean scores were shown in Table 3. After the ischemic injury, nNOS expressions in motor neurons significantly increased when compared with that in the control group ( $p=0.001$ ) (Table 3, Figure 5A \& 5B). Some motor neurons showed nNOS positivity in the SA group (Figure 5C, Table 3). A slight decrease in nNOS expression was observed in the SA-treated group when compared with the SCI/R group.

Neurological examination results. There was no change in the motor scores of the group treated with $10 \%$ ethanol before and after ischemia. All subjects were paraplegic. In the SA-treated group, 3 subjects received zero, 2 subjects received one point, and one subject received 2 points. As a result, the motor score was higher in the SA group, and this was interpreted in favor of healing (Graphic).

Discussion. Impairment of spinal cord energy metabolism, loss of aerobic glycolysis, accumulation of intracellular sodium and calcium, increase in lactate levels, production of free radicals, cell edema, and over activation of lipase and protease are seen during ischemia. Cell death is the inevitable result of the processes mentioned above. ${ }^{9,10}$ It is crucial to develop a treatment strategy before ischemia results in permanent neuronal damage. During ischemic injury, reactive oxygen components are inactivated by antioxidants such as SOD, CAT, GPx, and vitamins C and E. ${ }^{3}$ Still, neurons are very susceptible to oxidative damage, and their antioxidant capacity is limited. Many studies on molecules with antioxidant and anti-inflammatory effects to reduce permanent damage in ischemic models have recently been conducted.

Syringaldehyde is a polyphenolic compound from the flavonoid group. ${ }^{6}$ Huang et $\mathrm{al}^{11}$ have demonstrated the glucose-lowering effects of SA in diabetic rats. In a study by Farah and Samuelsson, ${ }^{12}$ it was shown that topical SA was as effective as using half of the acetylsalicylic acid in preventing auricular edema 

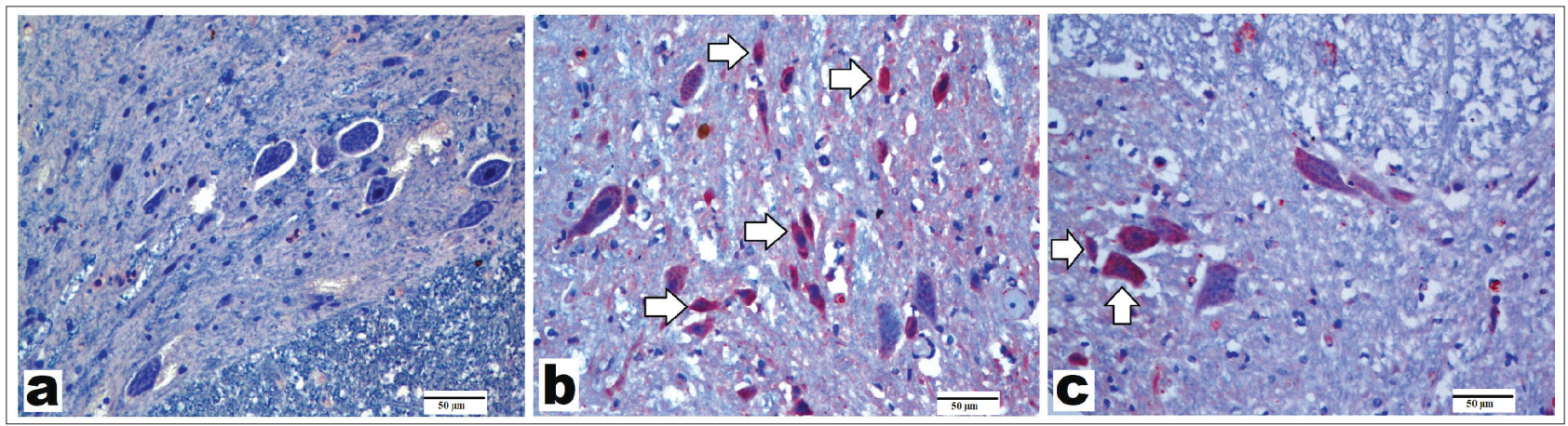

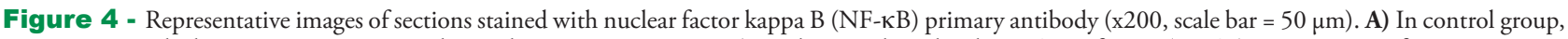
a little or no positivity was observed in motor neurons. B) In the spinal cord ischemia/reperfusion (SCI/R) group, most of motor neurons showed NF- $\mathrm{KB}$ positivity. C) In the syringaldehyde-treated ischemia group, a decreased number of immunopositivity than the SCI/R group was observed. Arrows refer to NF- $\mathrm{kB}$-positive staining in motor neurons.
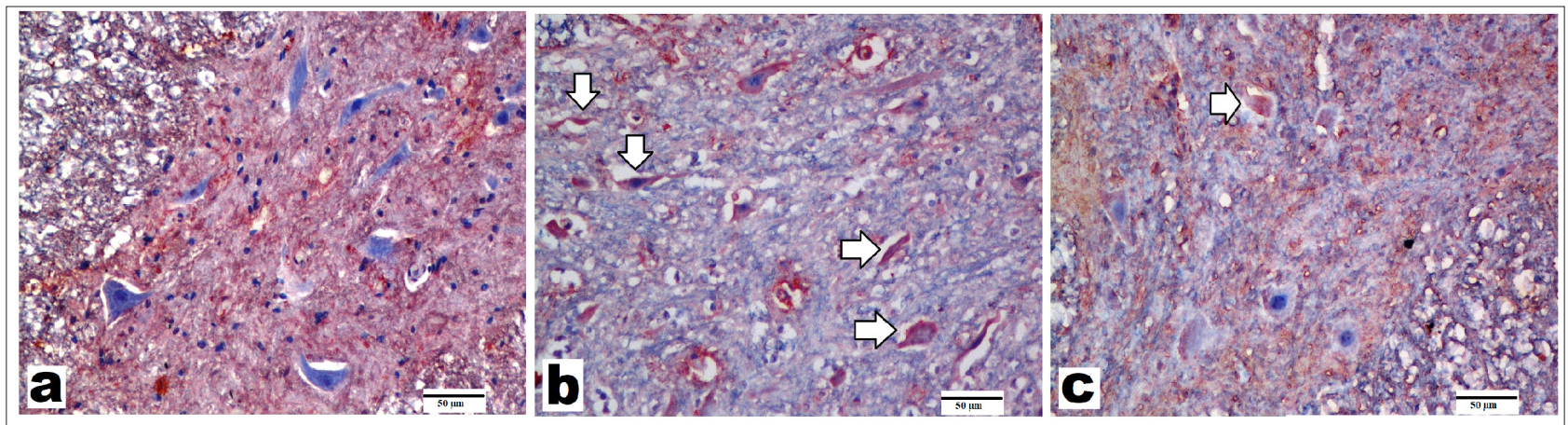

Figure 5 - Representative images of sections immunostained with neuronal nitric oxide synthase (nNOS) primary antibody (x200, scale bar $=50 \mu \mathrm{m})$. A) Control group showed a few nNOS-positive-stained motor neurons. B) Spinal cord ischemia/reperfusion (SCI/R) group showed strong nNOS positivity in degenerated motor neurons. C) Syringaldehyde-treated ischemia group showed decrease in nNOS expression compared with SCI/R group. Arrows refer to nNOS-positive-stained motor neurons.

produced by ethyl phenylpropionate in rats. According to their report, SA has been shown to have inhibiting characteristics on prostaglandin synthesis. Stanikunaite et $\mathrm{al}^{13}$ showed that SA extracted from Elaphomyces granulatus in a study with mouse macrophages inhibits COX-2 activity. Lee et $\mathrm{al}^{6}$ compared the polyphenolic compounds SA, quercetin, and trolox. In this study, SA showed an antioxidant effect 2 times higher than quercetin and 10 times stronger than trolox.

Autonomic, endocrine, metabolic, and immunological responses to harmful stimuli in order to achieve and maintain homeostasis of the body are regarded as responses to stress. Neutrophils activated by tissue destruction release numerous enzymes such as MPO, acid phosphatase, and elastase. ${ }^{14}$ Changes in the proportion of circulating leukocytes occur during this inflammatory response. In our study, SA treatment slightly decreased bleeding, and inflammatory cell migration in the SA-treated group was significantly decreased compared with that in the SCI/R group. Additionally, tissue healing was assessed histopathologically and immunohistochemically.

The effects such as hypoxia, acidosis, free radical damage, and membrane breakdown in the case of SCI can be shown biochemically. Besides, studies have shown anti-inflammatory properties of SA in normal creatures. Within the scope of this study, we investigated how SA administered under general anesthesia affected SOD, CAT, GPx and MPO activities and MDA levels in rabbits. Deficiency in oxygen uptake occurs in tissues with decreased blood flow. Tissue damage caused by oxygen deficiency in an ischemic condition increases with reperfusion due to increased oxygenation. Adenosine triphosphate (ATP) synthesis stops during ischemia. Decrease in mitochondrial ATP production leads to anaerobic shift of intracellular metabolism and intracellular acidosis. The slowing of ATP-dependent $\mathrm{Na}+/ \mathrm{K}+$ ion pumps leads to an increase in intracellular 
hydrogen. To compensate for increased hydrogen load, the non-ATP-dependent $\mathrm{Na}+\mathrm{Ca} 2+$ pump increases the amount of intracellular calcium. Increased calcium load activates many cytosolic proteases. Intracellular protease activation and reoxygenation of the tissues in reperfusion result in production of reactive oxygen species (ROS) that cause tissue damage. ${ }^{15}$

Due to its continued production, ATP is broken down into adenosine monophosphate and adenosine. Adenosine diffuses rapidly out of the cell and breaks down into inosine and hypoxanthine. Thus, the breakdown of high-energy phosphate compounds due to ischemia results in the deposition of purine metabolites such as xanthine and hypoxanthine in the tissue. This also results in the conversion of xanthine dehydrogenase to xanthine oxidase; because of this mechanism, the conversion of hypoxanthine to uric acid is carried out by xanthine oxidase, and molecular oxygen is used as electron acceptor in this reaction. ${ }^{16}$ It is known that xanthine oxidase causes oxidative damages such as edema, ischemia, and variability in vascular permeability in the brain. ${ }^{17}$

Another factor responsible for ROS formation in ischemia-reperfusion injury is the interaction between endothelial cells and inflammatory cells, primarily neutrophils, which are reperfused. Tissue inflammation during ischemia-reperfusion and proinflammatory mediators released by other cells in the vascular bed with endothelial cells lead to migration and adhesion of polymorphous nucleated leukocytes to the region. ${ }^{18}$ In many studies, increased neutrophils have been shown systemically in the ischemia-reperfusion-induced injury of organs such as the liver, ${ }^{19}$ heart, ${ }^{20}$ kidney, ${ }^{21}$ lung, ${ }^{22}$ and brain. ${ }^{23}$ Phagocytic leukocytes activated in response to ROS-induced inflammatory agents produce oxygen mediators as a result of a respiratory burst.

Nicotinamide adenine dinucleotide phosphate oxidase, which is responsible for ROS production, causes superoxide formation. Superoxide radicals are converted to hydrogen peroxide $\left(\mathrm{H}_{2} \mathrm{O}_{2}\right)$ with SOD and then to hypochlorous acid with $\mathrm{MPO}^{24}$ or to hydroxyl radical by Fenton reaction and are released to tissues. Greef et $\mathrm{al}^{25}$ reported the importance of antioxidant enzymes such as SOD, CAT, and GPx in the pathophysiology of ischemia-reperfusion to reduce ROS and prevent the damage of oxygen radicals to tissues.

In our study, we evaluated lipid peroxidation as well as antioxidant enzyme activities. In a review that discussed the association between lung ischemiareperfusion and oxidative stress, the dramatic reduction of SOD, CAT, and GPx enzyme activities after lung ischemia was elucidated by various mechanisms. ${ }^{26}$
Similarly, in a study that investigated the effects of melatonin against myocardial ischemia-reperfusion injury, it was found that the activity of SOD and GPx decreased significantly in ischemia-reperfusion after pinealectomy. ${ }^{27}$

Malondialdehyde, which is the most important product of lipid peroxidation, causes negative effects to ion exchange in the membrane. ${ }^{28}$ The degradation of lipid peroxides as a result of lipid peroxidation requires catalysis of transition metals. Lipid peroxidation can be induced by free radical sources and increases in the presence of transition metals in the plasma membrane and subcellular organelles. Hydroxyl radical formation as a result of Fenton reaction from $\mathrm{H}_{2} \mathrm{O}_{2}$ may initiate a chain reaction. ${ }^{29}$ Therefore, antioxidant mechanisms are activated in order to remove the radicals resulting from the damage. In a study by Vries et $\mathrm{al},{ }^{30}$ it was observed that lipid peroxidation increased and SOD and GPx activities decreased after ischemia-reperfusion during renal transplantation and cardiac valve surgery.

In a study that examined the effects of $n$-acetylcysteine and ebselen on the intestinal ischemiareperfusion injury in rats, MDA levels were increased in the ischemia-reperfusion groups, and SOD and GPx activities decreased. However, it was determined that there was a decrease in MDA levels and an increase in antioxidant enzyme levels after ebselen use. ${ }^{31}$ In another study that investigated the effects of curcumin on experimental intestinal ischemia-reperfusion injury, it was found that curcumin, which has antioxidant properties, significantly increased MDA levels as in the aforementioned study and increased SOD and GPx activities. ${ }^{32}$ Decreased CAT and SOD activities as a result of renal ischemia-reperfusion were observed in rats treated with silymarin. ${ }^{33}$

In our study, it was observed that SOD $(3.29 \pm 0.47$ $\mathrm{U} / \mathrm{mL} . \mathrm{mg}$ protein) and CAT $(13.99 \pm 1.10 \mathrm{U} / \mathrm{mL} . \mathrm{mg}$ protein) values were significantly reduced after SCI in rabbits, which similar to other studies in the literature. However, enzyme activities increased in the SA-treated group $(5.38 \pm 0.70 ; 21.31 \pm 2.32 \mathrm{U} / \mathrm{mL} . \mathrm{mg}$ protein). In accordance with the literature, it was observed that GPx enzyme activity decreased in the ischemia group in our study. But in the SA-treated group, a significant difference in GPx activity $(33.21 \pm 3.58 \mathrm{U} / \mathrm{mL}$.mg. protein) was observed when compared with the control group $(38.77 \pm 5.04 \mathrm{U} / \mathrm{mL} . \mathrm{mg}$. protein); in addition, a significant difference was also observed when compared with the ischemia group $(1.98 \pm 0.76 \mathrm{U} / \mathrm{mL}$.mg. protein).

An increase in MDA levels due to lipid peroxidation was observed. In ischemic rabbits treated with SA, it can be said that MDA levels decrease due to lowered 
lipid peroxidation activity. In ischemic rabbits treated with SA, it can be said that MDA levels decrease due to lowered lipid peroxidation activity. Therefore, we concluded that SA is a radical scavenger with antioxidant properties in the early period of SCI Myeloperoxidase, together with neutrophil activation, has bactericidal properties due to its hypochlorite formed from $\mathrm{H}_{2} \mathrm{O}_{2}$. Increased amounts of MPO cause serious damage to kidney, heart, and brain tissues. ${ }^{34-36}$ Therefore, increased amounts of MPO with the release of inflammatory mediators due to ischemia-reperfusion injury were also frequently found in the literature. A study by Williams et $\mathrm{al}^{37}$ found that MPO levels increased significantly after renal ischemia-reperfusion injury in rats. In our study, we showed that MPO levels were significantly increased in rabbits after ischemia but significantly decreased in rabbits treated with SA, in accordance with the literature. From this point of view, it should be possible to say that SA administration scavenges the ROS that appeared as a result of SCI and increases the antioxidant enzyme activities.

Caspase- 3 is a molecule that plays a role in the irreversible part of apoptotic pathway. ${ }^{3}$ That is why increased levels of caspase- 3 can be interpreted as a sign of apoptotic activity. Recent studies have shown that neuron loss was observed to be higher in SCI and brain injury if caspase-3 was activated. ${ }^{38}$ In our study, the increase in caspase-3-positive-stained neurons, apoptosis caused by SCI/R damage, and decreased caspase-3 expression in the SA-treated group compared with the SCI/R group can all be attributed to SA's inhibiting effect on apoptotic cell death.

It is known that NF- $\kappa b$ plays an important role in initiating immune and inflammatory response to cell injury. ${ }^{39}$ Nuclear factor kappa B is a commonly encountered transcription factor that is found in immune system cells controlled by histocompatibility complex genes. Members of NF-кb family play an active role in host defense and rapid gene expression. By inhibiting NF- $\kappa b$ complex that takes part in host defense and therefore limiting the inflammation in injury zone, the cells can be protected as a result. ${ }^{40} \mathrm{In}$ our study, when the SA-treated group was compared with the SCI/R group, NF- $\kappa \mathrm{B}$ expression decrease in tissues and consequently inflammatory response inhibition at the site of injury could be interpreted as partial protection of cells from the devastating effects of inflammation.

It has been shown that cell damage correlates with increased nNOS levels in ischemic neuronal injuries. Many agents that reduce nNOS levels were experimented to combat the cell damage caused by this increase. In our study, a decrease in nNOS expressions was observed immunohistochemically in the SA-treated group when compared with the SCI/R group. Taking this into consideration, we concluded that $S A$ acted as a neuroprotective agent by lowering nNOS levels.

Study limitations. The limitations of our study mainly arise from the focus on oxidative stress parameters and more detailed histopathological examinations and molecular studies are needed. In future studies, it is thought that more beneficial data will be obtained by evaluating the cytokines in the inflammatory pathway of the neural tissue.

In conclusion, we observed that SA reduced neuron loss by suppressing caspase-3, NF-kb, and nNOS expressions. It makes us think that when $\mathrm{SA}$ is administered, reduced caspase- $3, \mathrm{NF}-\kappa \mathrm{B}$, and nNOS expressions might cause inhibition of cytotoxic pathways and therefore cause a cytoprotective effect. These conclusions were statistically significant as evidenced by the results of the biochemical evaluation of SOD, CAT, GPx and MPO activities and MDA levels. We believe that our study will pave the way for further studies that explore effectiveness of SA with SCI/R model with sacrification at 72 hours and evaluate histopathological changes in subacute phase through quantitative methods.

As a result, our findings suggest that SA therapy may reduce oxidative stress and degenerative changes in the ischemic spinal cord. The fact that there is only limited number of studies on SA in the literature shows the need for new research in these different models.

Acknowledgment. This work was funded by the Scientific Research Coordination Unit of Çanakkale Onsekiz Mart University, Çanakkale, Turkey (Project Number: TSA-2015-438). We would like to thank Dr. Kaan Malçok for his invaluable assistance with translation, editing, proofreading, and statistical analysis.

\section{References}

1. Zivin J. Recent advances in stroke therapy. West J Med 1998; 168: 261-262.

2. Lo LW, Wilson DF. A micro-light guide system for measuring oxygen by phosphorescence quenching. Adv Exp Med Biol 2003; 540: 117-123.

3. Chan P. Reactive oxygen radicals in signaling and damage in the ischemic brain. J Cereb Blood Flow Metab 2001; 21: 2-14.

4. Wang Y, Zhang ZG, Rhodes K, Renzi M, Zhang RL, Kapke A, et al. Post-ischemic treatment with erythropoietin or carbamylated erythropoietin reduces infarction and improves neurological outcome in a rat model of focal cerebral ischemia. Br J Pharmacol 2007; 151: 1377-1384.

5. Freeman B, Crapo J. Biology of disease: free radicals and tissue injury. Lab Invest 1982; 47: 412-426. 
6. Lee CY, Sharma A, Cheong JE, Nelson JL. Synthesis and antioxidant properties of dendritic polyphenols. Bioorg Med Chem Lett 2009; 19: 6326-6330.

7. Simonyi A, Wang Q, Miller RL, Yusof M, Shelat PB, Sun AY. Polyphenols in cerebral ischemia: Novel targets for neuroprotection. Mol Neurobiol 2005; 31: 135-147.

8. Guth L, Zhang Z, Roberts E. Key role for pregnenolone in combination therapy that promotes recovery after spinal cord injury. Proc Natl Acad Sci U S A 1994; 91: 12308-12312.

9. Choi D. Ischemia-induced neuronal apoptosis. Curr Opin Neurobiol 1996; 6: 667-672.

10. Fisher AB, Al-Mehdi AB, Wei Z, Song C, Manevich Y. Lung ischemia: endothelial cell signaling by reactive oxygen species. In: Wilson DF, Evans SM, Biaglow J, Pastuszko A, editors. Springer, Boston (MA): Oxyg Transp Springer; 2003. p. 343-347.

11. Huang $\mathrm{CH}$, Chen MF, Chung HH, Cheng JT. Antihyperglycemic effect of syringaldehyde in streptozotocininduced diabetic rats. J Nat Prod 2012; 24: 1465-1468.

12. Farah M, Samuelsson G. Pharmacologically active phenylpropanoids from Senra incana. Planta Med 1992; 58 : 14-18.

13. Stanikunaite R, Khan S, Trappe J, Ross S. Cyclooxygenase-2 inhibitory and antioxidant compounds from the truffle elaphomyces granulatus. Phytother Res 2009; 23: 575-578.

14. Mehta J, Dinerman J, Mehta P, Saldeen TG, Lawson D, Donnelly WH, Wallin R. Neutrophil function in ischemic heart disease. Circulation 1989; 79: 549-556.

15. Ozcan O, Erdal H, Yonden Z. Biochemical Aspect of Oxidative Stress Related to Ischemia-Reperfusion Damage. Mustafa Kemal Üniversitesi Tip Dergisi 2015; 6: 23.

16. Parks DA, Williams TK, Beckman JS. Conversion of xanthine dehydrogenase to oxidase in ischemic rat intestine: a reevaluation. Am J Physiol 1988; 254: 768-774.

17. Lavelli V, Peri C, Rizzola A. Antioxidant activity of tomato products as studied by model reactions using Xanthine oxidase, Myeloperoxidase, and copper-induced lipid peroxidation. $J$ Agric Food Chem 2000; 48: 1442-1448.

18. Dworakowski R, Walker S, Momin A, Desai J, El-Gamel A, Wendler $\mathrm{O}$, et al. Reduced nicotinamide adenine dinucleotide phosphate oxidase-derived superoxide and vascular endothelial dysfunction in human heart failure. J Am Coll Cardiol 2008; 51: 1349-1356.

19. Serracino-Inglott F, Habib NA, Mathie RT. Hepatic ischemiareperfusion injury. Am J Surg 2001; 181: 160-166.

20. Schmid-Schönbein GW, Engler RL. Granulocytes as active participants in acute myocardial ischemia and infarction. Am J Cardiovasc Pathol 1987; 1: 15-30.

21. Hansson RO, Jonsson O, Lundstam S, Petterson S, Schersten T, Waldenström J. Effects of free radical scavengers on renal circulation after ischemia in the rabbit. Clin Sci 1983; 65: 605-610.

22. de Perrot M, Liu M, Waddell TK, Keshavjee S. Ischemiareperfusion-induced lung injury. Am J Respir Crit Care Med 2003; 167: 490-511.

23. Pan J, Konstas AA, Bateman B, Ortolano GA, John PileSpellman J. Reperfusion injury following cerebral ischemia: pathophysiology, MR imaging, and potential therapies. Neuroradiology 2007; 49: 93-102.
24. Parks DA, Granger DN. Xanthine oxidase: biochemistry distribution and physiology. Acta Physiol Scand 1986; 548: 87-99.

25. De Greef KE, Ysebaert DK, Ghielli M, Vercauteren S, Nouwen EJ, Eyskens EJ, et al. Neutrophils and acute ischemia-reperfusion injury. J Nephrol 1998; 11: 110-122.

26. Ferrari RS, Andrade CF. Oxidative stress and lung ischemiareperfusion injury. Oxid Med Cell Longev 2015; 2015: 590987.

27. Şahna E, Deniz E, Aksulu HE. Myocardial ischemia-reperfusion injury and melatonin. Anadolu Kardiyol Derg 2006; 6: 163-168.

28. Niki E. Antioxidant in relation to lipid peroxidation. Chem Phy 1987; 44: 227-253.

29. Placer CA, Cushman LL, Johnson BC. Estimation of product of lipid peroxidation (Malondy Dialdehyde) in biochemical systems. Anal Biochem 1990; 16: 259-264.

30. de Vries DK, Kortekaas KA, Tsikas D, Wijermars LG, van Noorden CJ, Suchy MT, et al. Oxidative damage in clinical ischemia/reperfusion injury: a reappraisal. Antioxid Redox Signal 2013; 19: 535-545.

31. Tunc T, Atabek C, Uysal B, Topal T, Erdogan E, Korkmaz A, et al. Sıçanlarda İntestinal İskemi/Reperfüzyon Hasarında N-Asetilsisteinin ve Ebselenin Etkileri. Turkiye Klinikleri J Cardiovasc Sci 2008; 20: 1-7.

32. Karabacak A, Oz AB, Akyuz M, Akyıldız HY, Akcan AC, Sozuer ME. Effects of curcumin in experimental intestinal ischemia reperfusion model on rats. Kolon Rektum Hast Derg 2013; 23: 186-191.

33. Senturk H, Kolankaya D, Sahin Y. The effect of silymarin on oxidative damage in rat kidney during renal ischemiareperfusion. Cankaya University Journal of Science and Engineering 2010; 7: 159-174.

34. Nagra RM, Becher B, Tourtellotte WW, Antel JP, Gold D, Paladino $\mathrm{T}$, et al. Immunohistochemical and genetic evidence of myeloperoxidase involvement in multiple sclerosis. $J$ Neuroimmunol 1997; 78: 97-107.

35. Baldus S, Heeschen C, Meinertz T, Zeiher AM, Eiserich JP, Münzel T, et al. Myeloperoxidase serum levels predict risk in patients with acute coronary syndromes. Circulation 2003; 108: 1440-1445.

36. Malle E, Buch T, Grone HJ. Myeloperoxidase in kidney disease. Kidney Int 2003; 64: 1956-1967.

37. Williams P, Lopez H, Britt D, Chan C, Ezrin A, Hottendorf R. Characterization of renal ischemia-reperfusion injury in rats. $J$ Pharmacol Toxicol Methods 1997; 37: 1-7.

38. Ferrer I, Planas AM. Signaling of cell death and cell survival following focal cerebral ischemia: life and death struggle in the penumbra. J Neuropathol Exp Neurol 2003; 62: 329-339.

39. Bethea JR, Castro M, Keane RW, Lee TT, Dietrich WD, Yezierski RP. Traumatic spinal cord injury induces nuclear factor-kappa B activation. J Neurosci 1998; 18: 3251-3260.

40. Baeuerle PA, Henkel T. Function and activation of NF-kappa B in the immune system. Annu Rev Immunol 1994; 12: 141-179. 